\title{
The Misanalogical Construction of Undergraduate Students in Solving Cognitive Conflict Identification Task
}

\author{
Andi Fajeriani Wyrasti ${ }^{1,2}$, Cholis Sa'dijah ${ }^{1 *}$, Abdur Rahman As'ari ${ }^{1}$, I Made Sulandra ${ }^{1}$ \\ ${ }^{1}$ Postgraduate School, Universitas Negeri Malang, INDONESIA \\ ${ }^{2}$ Mathematics Education, Universitas Papua, INDONESIA

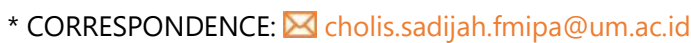

\begin{abstract}
The aim of this study is to investigate the misanalogical construction of undergraduate students in their cognitive conflict in doing a non-routine mathematical task. Qualitative methods were used in this research. Data were collected from 68 seventh semester undergraduate students of Mathematics Education Study Program, Universitas Negeri Malang by assigning them to accomplish the cognitive conflict identification task and interviewing them. It is found that five students have experience the autocognitive conflict. So that we made an indepth interview to these five students to trace the misanalogical construction in their cognitive conflict and found that one of them made the misanalogical construction, and she was Elsa. The investigation result from Elsa shows that she made several misanalogical construstions in her cognitive conflict in solving the task. They are misanalogical construction in set theory, misanalogical construction in fraction, and misanalogical construction in sequence.
\end{abstract}

Keywords: cognitive conflict, misanalogical construction, misanalogical construction in set theory, misanalogical construction in fraction, misanalogical construction in sequence

\section{INTRODUCTION}

The Construction of mathematical concept as a product of learning mathematics has an important role both in the learning and problem-solving purposes (Baser, 2006; Setianingsih et al., 2017; Subanji, 2015; Zhou, 2010). In learning process, students use their previous construction to build a more complete construction. It shows that this construction process occurs continuously. So that if there is an error in the previous construction, it will affect the next construction. In addition, students need good construction in solving the problem. Which means that a good construction could help students in solving the problem. However, the fact shows that the process of construction does not always work well. Some errors often occur in the construction process that they do, and it was studied by several researchers (Aksoy \& Yazlik, 2017; Bingolbali, et. al., 2011; Hasemann, 1981; Kar \& Isik, 2014; Maharani \& Subanji, 2018; Ndalichako, 2013; Novitasari, et al., 2018; Peled \& Shahbari, 2009; Özmantar, et al., 2009; Shein, 2012; Setianingsih, et al., 2017; Subanji, 2015). Ndalichako (2013) found that some students have difficulty in solving questions related to a fraction. They tend to confuse fraction concepts with whole number concepts. For example, in solving the addition of fraction, students add numerators and denominators separately. The same thing that was found by Özmantar, et. al (2009). Bingolbali, et.al. (2011) mention some causes of these errors. It is about prior knowledge or its deficiency, negative attitudes (prejudice), lack of motivation and interest, lack of ability, lack of self-confidence, dislike of math or the topics. These errors lead to misconstruction, as stated by Subanji (2012). He states that the misconstruction of a concept is a distortion from the formal concept in knowledge construction of the

Article History: Received 5 June 2018 • Revised 17 October $2018 \bullet$ Accepted 2 November 2018

(C) 2019 by the authors; licensee Modestum Ltd., UK. Open Access terms of the Creative Commons Attribution 4.0 International License (http://creativecommons.org/licenses/by/4.0/) apply. The license permits unrestricted use, distribution, and reproduction in any medium, on the condition that users give exact credit to the original author(s) and the source, provide a link to the Creative Commons license, and indicate if they made any changes. 
mathematical concept. This misconstruction can occur in learning or problem-solving. There were several types of misconstruction. One of them is misanalogical construction. The misanalogical construction occurs when students make mistake in analogizing a problem to another concept representation. For example, students were analogizing $(x+y)^{2}$ with $(x y)^{2}$. Because $(x y)^{2}=x^{2} y^{2}$, then $(x+y)^{2}=x^{2}+y^{2}$. In this case, students assume that $(x+y)^{2}$ and $(x y)^{2}$ as an analogous form. Wyrasti, et. al. (2016) also found that student has misconstruction about the concept of a sequence as arrangements of numbers that have a certain regularity or specific pattern. This pattern is associated with the pattern of arithmetic sequence and geometric sequence, not as a function. Consequently, students find found difficulties when conceiving to sequence $4,6,10,14,22,26,34,38, \ldots$. Students could not find the pattern, because of their misconstruction about the sequence.

The example above shows us that the misconstruction cannot be ignored. If this misconstruction is allowed, then it will have a serious implication for students, which means that it can damage the next construction process or prevent students while solving a problem. In this situation, interventions are needed when students are unable to solve the problems that caused by misconstruction (Djasuli, et al, 2017). For instance: this misconstruction can be improved by the teacher in learning mathematics in the classroom. Nonetheless when these misconstructions were carried out in the examination, students will make a mistake in answering the question. Repairing this misconstruction can be done by restructuring students' thinking structure. Subanji (2015) mentioned several strategies that can be done for this rearrangement. One of them is restructuring by using the cognitive conflict strategy. Some previous studies have discussed this rearrangement to create a conceptual change by using the cognitive conflict instruction (Akpinar, et al, 2009; Baser, 2006a; Bingolbali et al., 2011; Budiman, et al, 2014; Kang, et al, 2010; Kang, et al, 2005; Kang et al, 2004; Lee et al., 2003; Lee \& Byun, 2012; Lee \& Kwon, 2001; Lee \& Yi, 2013; Limon, 2001; Madu \& Orji, 2015; Maharani \& Subanji, 2018; Oh, 2011; Sela, 2008; Sela \& Zaslavsky, 2007; Shahbari \& Peled, 2015; Susilawati, et al, 2017; Toka \& Askar, 2002; Zazkis \& Chernoff, 2006, 2008). These studies generally discussed how to create a conflict situation in student's thinking structure to achieve a condition that known as conceptual change. The presence of anomalous situation as a key point to the occurrence of cognitive conflict at those studies stemmed from the intervention of teachers/researchers. This is not possible when students are taking an exam. They must be able to present an anomalous situation in the process of solving a problem in the examination. Previous studies have not discussed this, while a cognitive conflict is needed to repair students' misconstruction, especially in the examination. Wyrasti (2016) and Wyrasti, et. al. (2016) has described how cognitive conflict occurs in a student's thinking structure. Those research tells us that the presence of cognitive conflict appeared from and solved by the students themselves. Wyrasti (2016) and Wyrasti, et. al. (2016) also indicated that there was a misanalogical construction as the trigger of the cognitive conflict. This kind of cognitive conflict was called the autocognitive conflict as stated in Wyrasti, et. al. (2018). However, these studies did not discuss how the misanalogical construction and cognitive conflict occurs, and also how their position in the process of solving mathematical problems. Therefore, the aim of this research was to investigate undergraduate students' misanalogical construction in their cognitive conflict in doing the cognitive conflict identification task (CCIT). The cognitive conflict process discussed in this research focuses on cognitive conflicts that the anomaly situations are exposed by students themselves which are called as the autocognitive conflict.

\section{METHODS}

This is a qualitative research that described a student's autocognitive conflict in doing a non-routine task. The total of the participants in this research was 68 undergraduate students of the mathematics education study program, Universitas Negeri Malang who have taken calculus, number theory, and real analysis. They were asked to verbalize what they do and think throughout the problem-solving process (think aloud method). During the problem-solving process progresses, researchers noticed and noted the gestures of each student that were showed or disclosed by the subject, which shows the characteristics of the occurrence of cognitive conflict either in the form of the body movement that demonstrated by the subject or unusual phrases that levelled by the subject. These cues are used by researchers to investigate the conflicts that occur in students cognitive structure. Subsequently, interview processes were undertaken based on students works and the think-aloud recording that they have done. To get the effectiveness of think aloud method that used in this research, we paid attention to the interview technique and situation setting among the interview processes. These conditions help the subject to minimize the level of stress and tension. So that the subject does not feel depressed when the interview process takes place and can express anything in their mind that corresponds to the given problem. The results of these interviews are then analyzed and presented in this paper. 


\section{Subject Selection}

The subject in this research was chosen based on the predetermined criteria. The criteria for choosing students as the subjects were students who experience the autocognitive conflict and make the misanalogical construction. Subjects chosen stages will be described in the following stages. Firstly, based on the answer sheet and the think aloud record, we selected subjects that have experience the autocognitive conflict. Form this phase, five students were identified as having the autocgnitive conflict. After that, we trace the misanalogical constructions that done by the students with the autocognitive conflict. We found that one of them were have the misanalogical construction, and she was Elsa. Next, we designing an indepth interview to Elsa based on her answer sheet, think aloud and interview record to trace her misanalogical construction in the autocognitive conflict.

\section{Instrument}

In order to investigate students' cognitive conflict, we design this following non routine task.

Let $p$ be a prime number. Determine the solution set for every pair positive integers of $(x, y)$ such that $\frac{1}{x}+\frac{1}{y}=\frac{1}{p}$

The solution set of this problem are

$$
\left\{\left(-1+p,-p^{2}+p\right),\left(-p^{2}+p,-1+p\right),\left(1+p, p^{2}+p\right),(2 p, 2 p),\left(p^{2}+p, 1+p\right)\right\}
$$

This task has been validated by one mathematics education expert lecturer and one mathematics expert lecturer. This problem was chosen because this type of non-routine question can be used to reveal the existence of the autocognitive conflict process of students and the misanalogical construction.

\section{RESULT AND DISCUSSION}

We present the data with the analysis and also the discussion of the data in this section. Based on her answer sheet, we know that she tried to find the solution by dividing $x$ and $y$ values into four cases. First case is "while $x=y=1$ for $x, y \in \mathbb{N}$ ", second case is "while $x=y=2$ for $x, y \in \mathbb{N}$ ", third case is "while $x=y \neq 2$ for $x, y \in \mathbb{N}$, and the last case is "while $x \neq y$ for $x, y \in \mathbb{N}$ ". On her answer sheet, we also found that she gives her reason about her answer but she didn't make the conclusion of her overall work. In other word, she didn't make her conclusion about the solution of the given problem. Based on her think aloud recording dan work paper, we create an in-depth interview to her, to know the process of the misanalogical construction in her autocognitive conflict while doing the task.

Firstly, we asked her reason about dividing the problem into some cases. She said that based on the information that she found from the given problem, there are $x, y \in \mathbb{N}$. It means that $x, y \in\{1,2,3,4,5, \ldots\}$. So the possible value for $x$ and $y$ can be divided into four groups, they are $x=y=1, x=y=2, x=y \neq 2$, and $x \neq y$. She said too that this division helps him to simplify the process of finding the solution of the equation.

Subject starts her solving problem by solving the first case. For the first case, she found that $p=\frac{1}{2}$. Then she conclude that because $\frac{1}{2}$ is not the prime number, so $x=y=1$ was not the solution (subjects work for the first case can be seen in Figure 1). She verbalize her answer and give her reason about her answer. Here is the quotation form her work paper for the first case. 


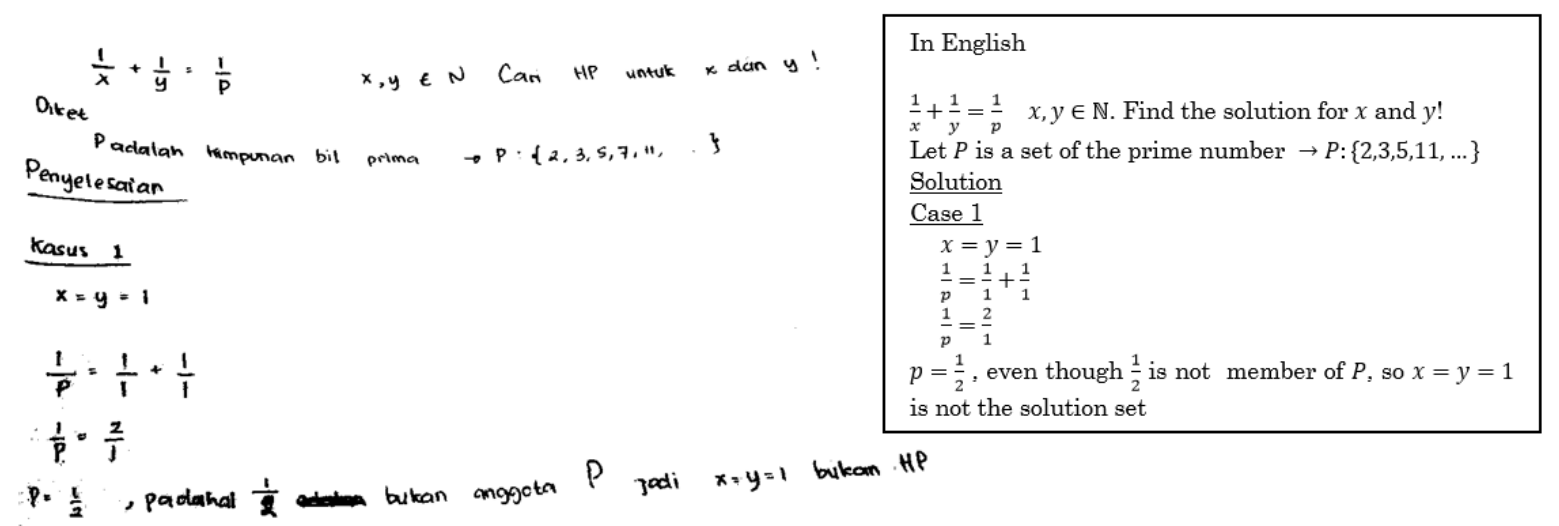

Figure 1. Subject's Work for The First Case

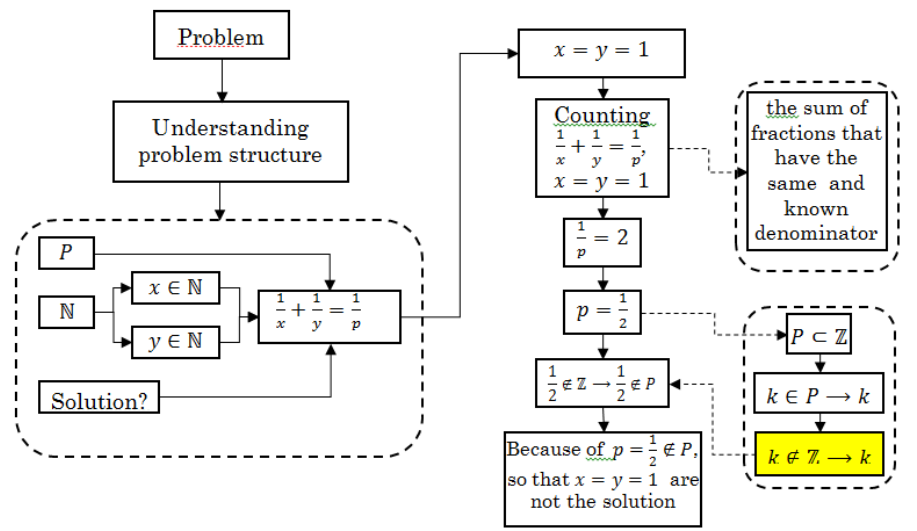

Figure 2. Subject's Thinking Structure for The First Case

Subject (S): For the first case, $x=y=1$, (pointed to her work paper) $\frac{1}{x}+\frac{1}{y}=\frac{1}{p}$ and $x=y=1$ means that $x=1$ and $y=1$, so $\frac{1}{p}=\frac{2}{1}$. Or we can say $p=\frac{1}{2}$. Here, $x=y=1$ are not the solution because $\frac{1}{2}$ is not a prime number.

In-depth interview result to her reason for the first case shown that subject try to used the set theory to summarize this first case. Here is the quotation.

S: I have learn before about elements of sets, that is if a set A included in set B, means that every elements of A must be included in set B.

R: What is that mean?

$\mathrm{S}$ : It means that if there is an element, a number for example, is not a member of $\mathrm{B}$, so that number is not a member of A. That is, because of $\frac{1}{2}$ is a fraction so that $\frac{1}{2}$ is not an integer. Consequently, $\frac{1}{2}$ is not a prime number.

An investigation result for the first case indicate that subject tried to use her prior knowledge about the set theory, specially subsets theory. In this case, we found that she did not show any cognitive conflict. Her thinking structure for her first case can be seen at Figure 2.

Figure 2 shows us that subject has enough prior knowledge to solve the first case. She tried to solve her first case by using the sum of the same and known denominator fraction, because she know that $x$ and $y$ were natural number and the prime number $p$. After found that $p=\frac{1}{2}$, she tried to use her prior knowledge about the set theory, and then made a conclusion for the first case. In this case, she did not made the misanalogical construction nor cognitive conflict. However, the potential for the emergence of her cognitive conflict in second case began here, while she used her knowledge about the set theory.

Next, for the second case, subject tried to solve her second case by using the sum of the same and known denominator fraction (her work can be seen in Figure 3). Figure 3 tells us that at the end of the solution at 


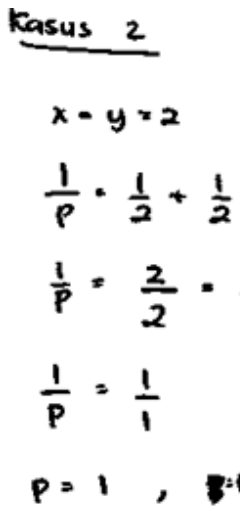

Figure 3. Subjet's Work for The Second Case

the second case, subject made mistake when made the conclusion that 1 is a member of the prime number set. Her answer's explanation indicate that her cognitive conflict proceed form an error in analogizing the resembling form of the set theory that used in her first case. It can be seen from the excerpts of her statements in her think aloud result and indepth interview as follows.

"I have explain at the first case that $k \notin \mathbb{Z} \rightarrow k \notin P$. Because of 1 is an integer so that 1 is a member of primes. The same case for 2 and 3, 2 and 3 respectively are primes because 2 and 3 are also integers"

Based on this quotation, it can be seen that she made a mistake in analogizing $k \in \mathbb{Z} \rightarrow k \in P$ form with $k \notin \mathbb{Z} \rightarrow k \notin P$ form. In this part, she considers like that because she thinks that $k \in P \rightarrow k \in \mathbb{Z}$ is equivalent to $k \notin \mathbb{Z} \rightarrow k \notin P$ so that it is analog to $k \in \mathbb{Z} \rightarrow k \in P$ too. Consequently, she concludes that "Because of 1 is an integer so that 1 is a member of primes. The same case for 2 and 3,2 and 3 respectively are primes because 2 and 3 are also integers". Actually, she has her own concept about the set of the prime number, but she was affected to the analogy she has done. Until this stage, she has been very convinced of her answer. She did not realize that she had made a misanalogical construction in her process of the solving problem.

Furthermore, this misanalogical construction becomes a trigger of her cognitive conflict when she found that there were the other integers, i.e. $4,6,8,9,10$ which are not the members of prime numbers. Here is a snippet of her expression.

"ups, wait a minute... there are 4, 6, 8, 9, and 10 are also integer members, but not prime numbers. What about the statement before?"

"hmmm, this is not accordance to this (pointing to her work)"

Her expression shows us that the anomaly situation comes here, and it was " $4,6,8$, 9, and 10 are also integer members, but not prime numbers". This anomaly situation comes from her self. In this stage, it can be seen that she can realized the anomaly situation and exposed it. She was aware that there were the conflicting ideas she made. After that, she tried to manage this anomaly situation and her previous trust from the analoging process. This is indicated in the following excerpt of her statement.

"hmmm, is that something wrong? Which one is wrong? Can I combine this two situation? Or choose one of them?"

Based on this excerpts, it can be seen that her cognitive conflict was exposed on her own consciousness to the present of anomaly situation due to her ability to connect the problem with the other concepts that she has. In this point, she wondered whether to combine this two case (because she believed that both of them to be right) or chose one of them (because both are conflicting). Finally, here is her decision.

"I think that I made a mistake here (pointing to the analogy process)."

The existence of mistakes in analogizing the concept of the subject is further reinforced by the explanation of the subject as follows. This footage also shown us that in resolving her cognitive conflict, she tried to relate what it is facing to other concepts in set theory, which is about contraposition.

"I thought before that $k \notin \mathbb{Z} \rightarrow k \notin P$ was just the same as $k \in \mathbb{Z} \rightarrow k \in P$. Hmm.. it turns out (pointing $\mathrm{k} \notin \mathrm{Z} \rightarrow \mathrm{k} \notin \mathrm{P}$ ) an implication that can not be flipped back arbitrarily. There are rules so that the meaning of the statement is the same." 


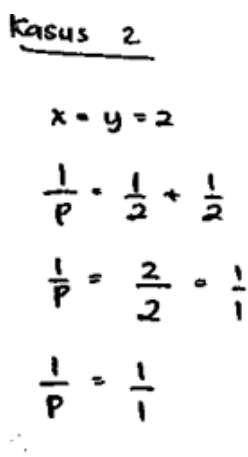

In English
$\begin{aligned} & \text { Case } 2 \\ & x=y=2 \\ & \frac{1}{p}=\frac{1}{2}+\frac{1}{2} \\ & \frac{1}{p}=\frac{2}{2}=\frac{1}{1} \\ & p=1.1 \text { is not a member of } P \text {. so that } x=v=2 \text { is not the solution }\end{aligned}$

$P=1$, adala lan banggota $P$ sehingga $x-y=2$ adalah Hip

Figure 4. Student's Work After Her Cognitive Conflict

In this second case, she can solve her own cognitive conflict and can renew her previous concept, in the sense that she can improve and upgrade her knowledge. Subject was success in solving her cognitive conflict and upgraded her prior knowledge. Here is the trailer

"So, if there is a number $c$ which is a member of an integer, not necessarily $c$ is a prime number too."

In this stage, she tried to relate her cognitive conflict resolution to her prior knowledge about the set of prime numbers. After has a new knowledge structure that if $c$ is an integer, it is not always a prime number, she checks the previous answer. In this checking process, she found that there was a mistake, and then rectified her previous answer. The success of the subject in resolving her cognitive conflicts is accompanied by her success in correcting the previously mistakes on conclusions for the second case (Figure 4). The snippet of her think aloud for this statement as follows

"Oh, this answer is wrong too. It should not be a prime even though it is an integer (pointing to 1 in her answer). So $\mathrm{x}=\mathrm{y}=2$ does not belong to the set of solutions."

Figure 4 shows us that this subject made a correction to her answer after she run into her cognitive conflict. She add letter "b" in front of the word "anggota" which means "bukan" or "not", and letter "B" in front of "HP" which means "Bukan" or "not". So, she conclude that " 1 adalah b.anggota P sehingga $x=y=2$ adalah BHP" which imply that 1 is not a member of the prime number set, so that $x=y=2$ is not the solution. All process of the misanalogical construction in her autocognitive conflict for the second case can be seen in Figure 5.

Figure 5 shows us that in this second case, formerly, she was not aware of any mistakes in analogizing concept, and this is believed to be a truth while doing the task. But then the anomalous situation emerged and she realized it as a contradiction to her previous convictions. Her autocognitive conflict occurs due to the contradiction between the new concept constructed that we know it was the misanalogical construction, with the structure of her previous knowledge about the membership of integers and primes. This cognitive conflict can be solved and she was able to upgrade her previous concept. And at the end, she can solve this second case. 


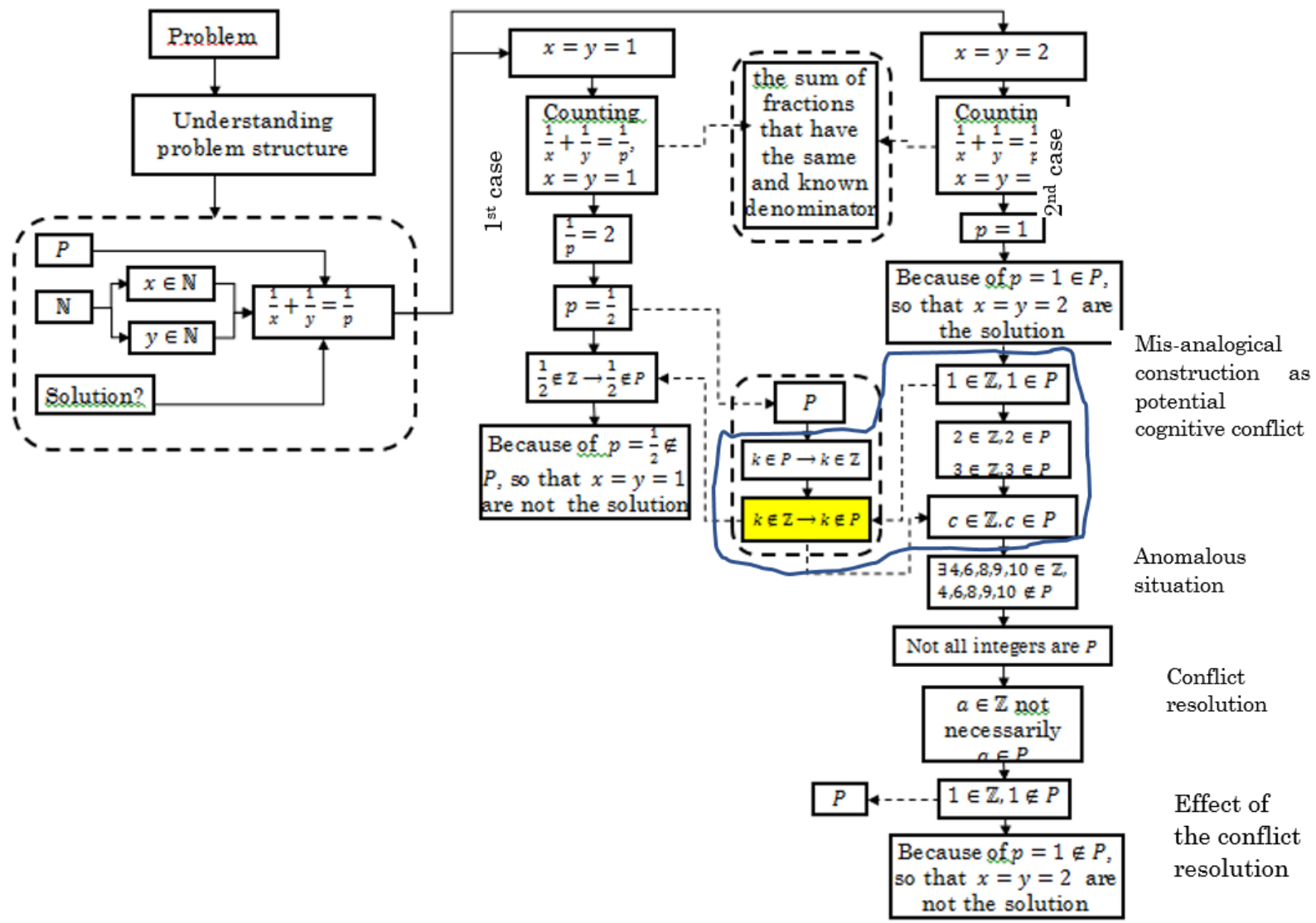

Figure 5. Subject's Thinking Structure for The Second Case

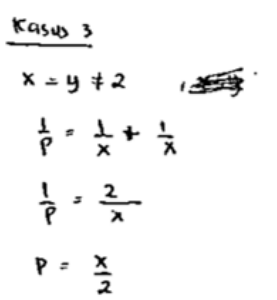

aclahal

adalah bilangran asli, dain $p$ adatiah bilemegan prima yoing

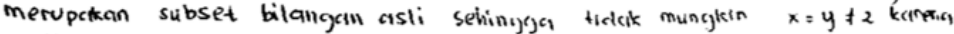

pasti akan menghasilkan desimal

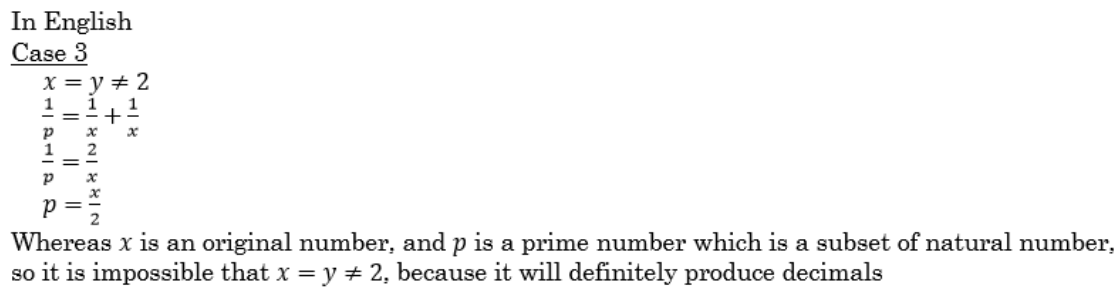

Whereas $x$ is an original number, and $p$ is a prime number which is a subset of natural number, so it is impossible that $x=y \neq 2$, because it will definitely produce decimals

The misanalogical construction also occurs in the third case. As in the second case, formerly, she was not aware of her mistake in analogizing the form of "resembling" a fraction as a fraction. She interpreted that $\frac{x}{2}$ was a fraction, which only produce a decimal number, not an integer. Meanwhile, according to her understanding of the problem, $p$ is a prime number, which is part of the natural number. The results of her work in the third case can be seen in Figure 6 .

Figure 6 shows us that this subject made a mistake in making conclusion on her calculations. On her calculation, she found that $p=\frac{x}{2}$ as a result of $\frac{1}{x}+\frac{1}{y}=\frac{1}{p}$, for $x=y \neq 2$. According to this subject, $x$ was a member of the natural number, so that $\frac{x}{2}$ will be equal to decimal number. Meanwhile it was known that $p$ is the prime number, which is a subset of the natural number. She was not aware of this error, even believes it as a truth. Here's a snippet of her think aloud result. Then she concluded her work for the second case that the solution for $x=y \neq 2$ was an empty set. 


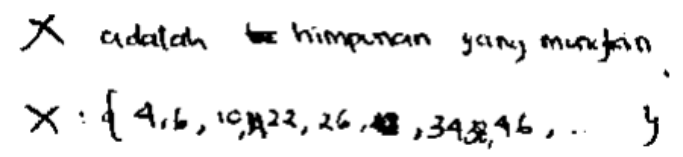

Figure 7. Subject's Note for The Third Case

"Here I got that $p$ is a fraction, because $x$ is the real number so $p=\frac{x}{2}$ must be decimal. We know that $p$ is a subset of $\mathbb{N}$. Thus, it is not possible for $x=y \neq 2$ “

"So, the set of solutions for the second case $x=y \neq 2$ is an empty set."

Until this step, she was still believe in her answer. She did not realize that something went wrong while constructing the concept of the fraction. She did not pay attention to the requirement that $x$ is a natural number. It means that there are $2 n$ which allow $p=\frac{x}{2} \in \mathbb{N}$. She was only affected by this rational form. When in fact, she has enough knowlegde to construct the concept of this fraction when facing $\frac{x}{2}$ form while solving the second case. And she believes this misanalogical construction as a truth.

An anomaly situation was present when she reminded to the pre-resolution of her cognitive conflicts in the previous second case. Her video recorded shows that she made some gesture and expression which indicates the occurence of the cognitive conflict.

"(scratching his head and fixing his hijab) hmmm ... wait a minute. (tapping on the table) seems like something weird here. (flipped over the answer sheets and made a scratch on the paper)."

"This is not as I thought before (tapping on the table and occasionally rubbing his nose). Hmmm..."

Furthermore, she was interviewed related to the piece of her think aloud recorded. At the time of interview, she admitted that at that moment, she remembered when resolving her conflict at the second case. She recalled that there was $x=2$ which allows $\frac{x}{2}$ as the integer, ie 1 . But since 1 is not a prime number, it has not changed her belief to her answer. Then she tried another even integer, which is 4 , and obtained $p=2$ which is a prime number. Finally, she was aware of this anomalous situation as something contrary to what he has concluded before. She was aware of the presence of the anomalous situation and began to doubt her previous convictions. In this stage, she acknowledged this anomaly situation as a truth and made as a pre-resolution of her cognitive conflict. Here are the trailer of the indepth interview.

"This is (pointing to the video) while I remember my answer at the second case that there are 2, 4, 6,48 , and 10 , which allows $\frac{x}{2}$ not the decimal. So I tried for 2 . I got $\frac{x}{2}=1.1$ is not a prime number as I thougt at my second case."

"At the beginning, I had no doubt to my answer. But then I tried for $x=4$ and got that $\frac{x}{2}=2$ is prime number. In this time, my opinion to my answer had started to falter. Then I try to choose $x=6,8,10$ and I got 3,4,5. 3 and 5 were prime number. At that moment, my confidence about my answer really collapsed."

"So, what I thought was wrong. There is $x=4,6,8,10$, which allows $p=\frac{x}{2}$ to generate integers. It means that there are some $x \in \mathbb{N}$ which is satisfy $p=\frac{x}{2} \in \mathbb{Z}$ while $p \in P$ (smiling) “

Subject could find her cognitive conflict resolution based on her previous cognitive conflict pre-resolution. She successfully used what was obtained in her previous cases to resolve her cognitive conflict. Furthermore, this cognitive conflict resolution became the potential cognitive conflict for her next cognitive conflicts when she tried to find the value of $x$.

The next stage of conflict also occurs when she tried to analogize the form that she was facing with her previous sequence concept. At this stage of the cognitive conflict, the anomaly situation arised as a result of the subject's work, in this case it was the previous cognitive conflict resolution that there is $x$ satisfying $p=$ $\frac{x}{2} \ni p \in P$. Then she tries to enumerate one by one some possible $x$-values, without realizing that $p=\frac{x}{2} \rightarrow x=$ $2 p$. Then she found a set of $X$ as in Figure 7 .

Figure 7 shows us that subject found a set of possible $x$-values, there are 4,6,10,14,22,26,34,38,46. The member of this set were derived from the experimental results as a continuation of her previous cognitive conflict. Subject recognized the Set $X$ as a sequence, then try to find the pattern of the sequence. 
Figure 8. Subject's work in finding the suitable $\boldsymbol{x}$
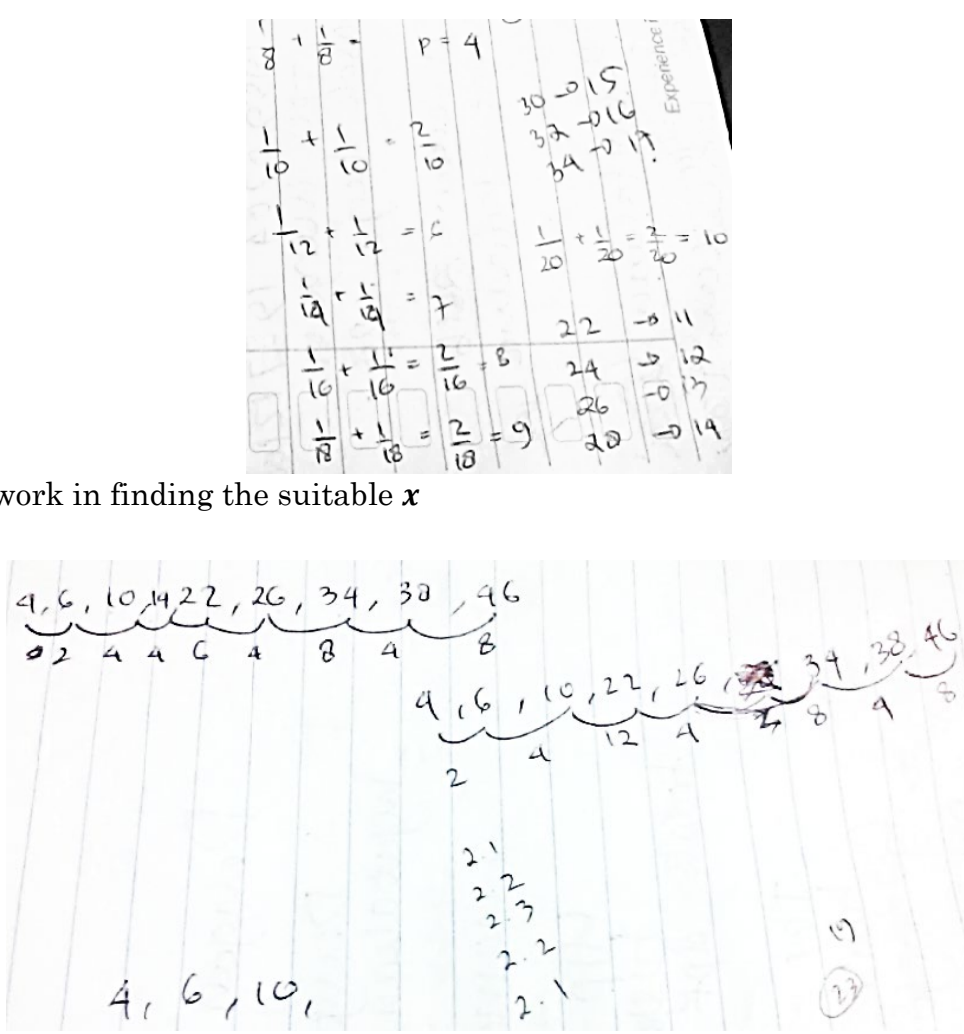

Figure 9. Subject's note to find the pattern of the series

"here I have a series number 4,6,10. I have to find another suitable $x$."

Formerly, subject just have 4,6, and 10 as the possible $x$ value that identified as a series. Then she tried to find the next $x$ value that satisfies the equation. In Figure 8, we can see the snippet of her ways to find the other $x$ by trial one by one even number.

Figure 8 said that subject try to find the suitable $x$ by trial one by one of the even number. It look like very complicated because she must try one by one for every even number. So she decided to find the pattern to make it easier.

"it is very difficult for me to find the other $x$ by this way."

"okay, here I found some suitable value for $x$. They were 4,6,10,14,22,26,34,38,46. I had to looking for the pattern to make easier to find the other possible $x$ values."

“4,6,10,14,22,26,34,38,46, here I found 2,4,4,6,4,8,4,8. What next?" (see Figure 9)

Figure 9 shows us that the subject used her previous knowledge about arithmetic and geometric sequence to find the pattern. Based on the indepth interview, she stated that the sequence is a series of patterned numbers. The pattern is like the arithmetics and geometrics sequence. So she used it here but she found that it is difficut for her to find the pattern by this way. She recognized this series number as the sequence but also recognized that it was contrary to her previous knowledge and was believed as a truth about the sequence. She believed that there are only two kinds of sequence. Here's a snippet of her think aloud for this problem.

"This (pointing to members of the Set $X$ ) looks like a sequence. 4,6,10,14,22,26,34,38,46. It was a series. But this (appointing members of $X$ ) does not have a pattern like arithmetic sequences as well as geometric sequences. I have searched the pattern, but I did not meet the pattern of the $n^{\text {th }}$ series."

She was not able to resolve her cognitive conflict at this second stage of conflict in the third case. She can not manage the contradiction between her previous concept about the type of the sequence and the existence of the other number series, but this series is not the arithmetic sequence, nor the geometry. Eventually, she failed to settle the third case. In this stage, she made a blunder in constructing the sequence concept. This is became the cause of her failure in solving her cognitive conflict. She constructed the sequence as a series of number that arranged in particular pattern. If her concept construction of the sequence was correct, then while found 4,6 and 10 at the beginning, she will be realized that $X$ was the sequence of $2 p$. Actually, she need 


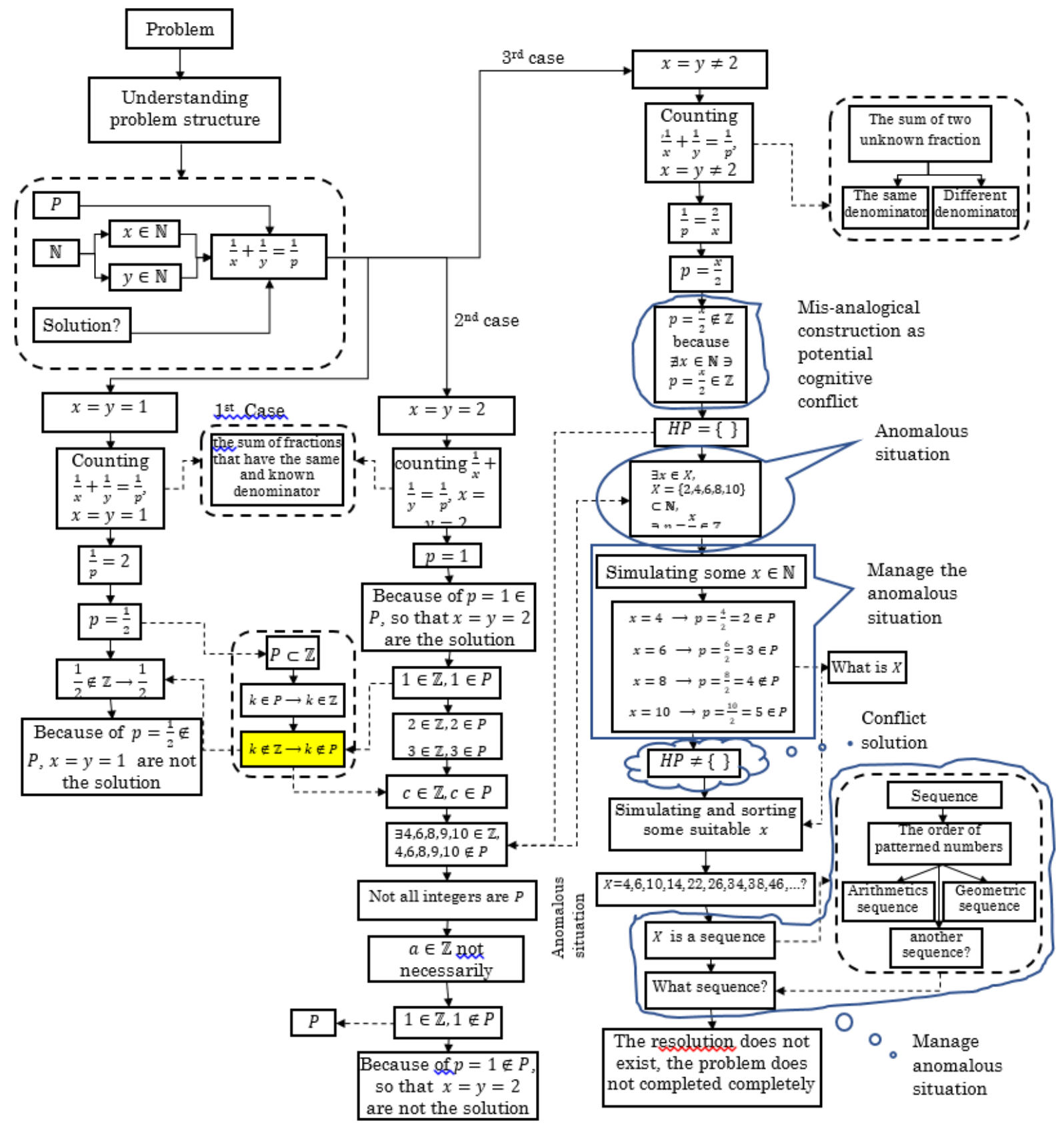

Figure 10. Student's Thinking Structure for The Third Case

an intervention in this situation, as stated by Djasuli, et.al. (2017). The structure of her thought for the third case can be seen in Figure 10.

Figure 10 stated that the misanalogical construction of the subject happen twice at the third case. The first misanalogical construction occurs while she analogizes $\frac{x}{2}$ as $\frac{1}{2}$. Whereas, the second misanalogical construction occurs when he analogizes the sequence as the arithmetics dan geometrics sequence. Both of these misanalogical constructions became her potential cognitive conflict. For the first misanalogical construction, the cognitive conflict occurs when she realized that there were $2,4,6,8$, and 10 so that $\frac{x}{2}$ is not decimal anymore. This awareness came from her cognitive conflict resolution at the second case. Subject success to solve her cognitive conflict in this stage. But next, it become the anomalous situation to the next cognitive conflict. While she try to simulating and sorting some suitable $x$, she found a set $X$ that consist of $4,6,10,14,22,26,34,38$ and 46 . She admited $X$ as a sequence. The cognitive conflict occurs when she tried to find 


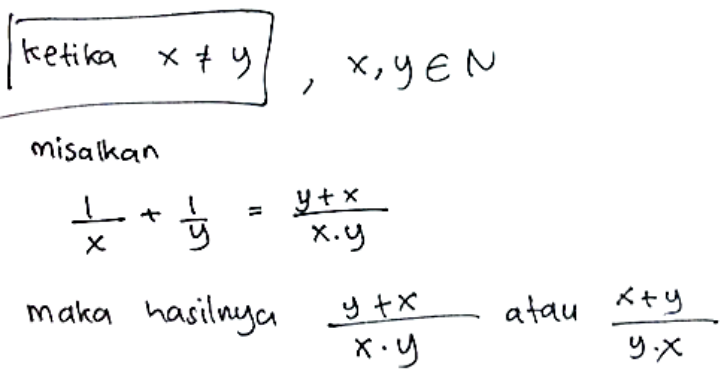

Figure 11. Subject's Answer For The Fourth Case

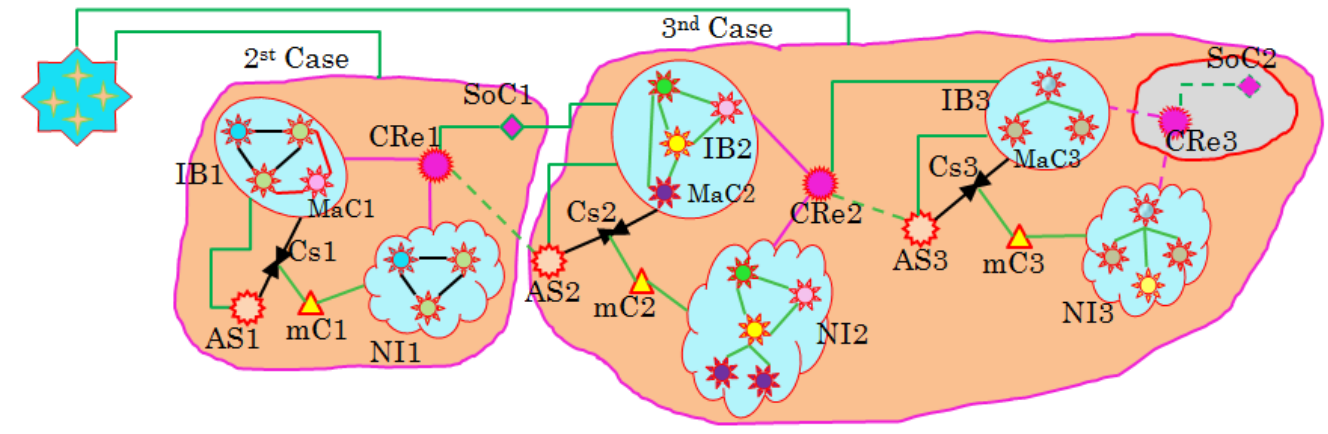

Figure legend :

IB $x$ : Initial believe for the $x^{\text {th }}$ Cognitive conflict NI $\quad$ : New idea $x^{\text {th }}$

AS $x$ : Anomalous situation for the $x^{\text {th }}$ cognitive conflict CRex : Conflict resolution $x^{\text {th }}$

Cs $x$ : Conflict stage $x^{\text {th }} \quad$ SoC $x \quad$ : Solution for $x^{\text {th }}$ case

$\mathrm{mC} x$ : Manage Conflict $x^{\text {th }} \quad$ MaCx : Misanalogical Construction $x^{\text {th }}$

Figure 12. The Schema of Subject's Misanalogical Construction in Cognitive Conflict

the pattern of X. Based on her previous construction about the sequence, she did not find the right pattern of $\mathrm{X}$. She recognized the contradiction between her knowledge about the sequence and the new sequence she just meet. This second cognitive conflict can not be resolved by subject. Consequently, she can not solve her third case.

In the fourth case, the subject still tried to find a solution. Figure $\mathbf{1 1}$ is her answer to the fourth case. However, she failed to complete the fourth case because she had felt frustrated due to the second conflict in the third case. In this case, he found that $1 / p=(y+x) / x y$ or $1 / p=(x+y) / y x$. This results eventually lead her to conclude that the solution set of this case is an empty set. In this case, she could no longer afford to think more about the answer in this case. This is due to the saturation experienced by the subject due to the cognitive conflict in the third case. Therefore, there was no cognitive conflict in this case. Ultimately, it becomes the end of her effort to solve the task.

Overall, the schema of her misanalogical construction in her cognitive conflict can be seen in Figure 12. Figure 12 stated that the misanalogical construction of the subject occurs three times, once in the second case and twice in the third case. The misanalogical construction happened because of her inability in analogizing a concept to the problem encountered. The first misanalogical construction is misanalogical construction in kontraposition. In this misanalogical construction, subjek analogize $k \in \mathbb{Z} \rightarrow k \in P$ form with $k \notin \mathbb{Z} \rightarrow k \notin P$ form. She considered like that because she thinks that $k \in P \rightarrow k \in \mathbb{Z}$ is equivalent to $k \notin \mathbb{Z} \rightarrow k \notin P$ so that it is analog to $k \in \mathbb{Z} \rightarrow k \in P$ too. This misanalogical construction was not realized but must be repaired by this subject herself. Subject could realized it while meet the anomalous situation and then become a conflict when she recognized the anomalous situation. Finally, after manage the cognitive conflict, she can repaired her misanalogical construction and resolved her cognitive conflict. The second misanalogical construction is misanalogical constructionin fraction. In this misanalogical construction, subject analogize the $\frac{x}{2}$ form as the fraction, so that the result of that form must be a decimal number. Subject did not realize this misanalogical construction. Then the anomalous situation comes from her awareness to her previous work at the second case. The cognitive conflict happened while she recognized that this anomaly situation contrary to her previous thinking structure, that we know it was a misanalogical construction. Then she manage it and success in 


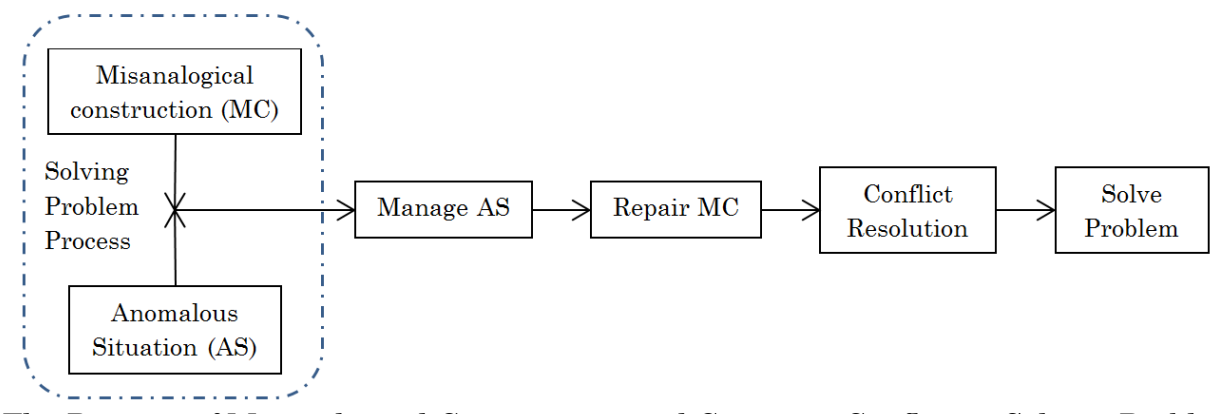

Figure 13. The Position of Misanalogical Construction and Cognitive Conflict in Solving Problem

repairing her misanalogical construction. Finally, she can resolve her cognitive conflict. These two cognitive conflict were similar to that expressed by Lee, et. al. (2003) that the existence of the cognitive conflict can be constructive to student's concept. In this point, subject success to reconstruct her misanalogical construction to the true construction due to cognitive conflict. But it will be contrary to the last misanalogical construction. The last misanalogical construction is misanalogical construction in sequence. Subject analogize the sequence as an arithmetic and geometric sequence. This become a contradiction while she faced the other series that she recognized also as a sequence, but it was not a sequence as in her inital believe. Subject tried to manage this conflict, but she failed in manage it. So that she failed in repairing her misanalogical construction about sequence. The impact is that the subject is unable to resolve the cognitive conflict. Finally, she also failed in solving the task. This shows that the existence of the misanalogical construction cause students have difficulties to complete the task. This case is similar to Subanji (2015) which states that misconstruction in solving problems reflect the error of learning mathematics. Conversely, if she can repair her misanalogical construction and have a correct construction about the sequence, so that she cand find the correct pattern of the sequence. Therefore, investigating sudent's misconstruction is important to do. The position of the misanalogical construction and the cognitive conflict in solving problem process can be seen in Figure 13.

Figure 13 shows us about how misanalogical construction impacts to the problem solving process and how the role of the cognitive conflict in the problem solving process. From this research, we can see that if the misanalogical construction occurs and did not receive a special attention, then the student could not complete the assigned task. This will be different if in the process of problem solving, student is able to find and realize the existence of the anomalous situation that lead to cognitive conflict, and success to resolve it. In the learning process, this anomaly situation can be raised by the teacher, as done by Akpinar et al., 2009; Baser, 2006; S. Kang et al., 2004; Lee et al., 2003; Limon, 2001; Madu \& Orji, 2015; Maharani \& Subanji, 2018; Susilawati et al., 2017; Toka \& Askar, 2002; Zazkis \& Chernoff, 2008, 2006. However, while students must complete the assignment in the examination for example, they must be indenpendent and able to find this anomaly situation. Wyrasti (2016) and Wyrasti, et. al. (2016) has describe about it, that students have the ability to emerge and realize the contradictory situations, resulting in cognitive conflict. Wyrasti, et. al. (2018) calls this cognitive conflict as the autocognitive conflict.

\section{CONCLUSION}

Misanalogical construction can occur in the solving problem process. In this study, misanalogical construction occurred three times. They were misanalogical construction in set theory, misanalogical construction in a fraction, and misanalogical construction in sequence. They became the initial believe of the subjcet, respectively. They were interrelated and continuous. Then, these three misanalogical constructions also turn into cognitive conflict when the subject was aware of something that was contrary to her initial believe. In this research, the misanalogical construction can be revealed due to the presence of anomalous situations that subject encounter while doing the task. This anomaly situation is realized by the subject. So that there was a contradiction between her initial believe (which is identified as misanalogical construction) and the anomaly situation that is present. The cognitive conflict that can be resolved by the student, can help her to reform her misconstruction into the true construction. On the other hand, the unresolved cognitive conflict cannot help a student to repair her misconstruction into the true construction. Meanwhile, the unrepaired misconstruction after the cognitive conflict made student fail to find the solution of the task. The existence of this misconstruction is not realized by the student. Therefore, it is important to habituated student to find and realize the anomalous situations that are a contradiction to the misconstruction while working on 
a task. How to familiarize students to form their alilities to bring out their autocognitive coflict and find its resolution to obtain the conceptual change, is still an opportunity for further research.

\section{ACKNOWLEDGEMENTS}

This work was funded by research grant disertation from DIRJEN Penguatan Riset dan Pengembangan Kementrian Riset, Teknologi, dan Pendidikan Tinggi Republik Indonesia.

\section{Disclosure statement}

No potential conflict of interest was reported by the authors.

\section{Notes on contributors}

Andi Fajeriani Wyrasti - Postgraduate School, Universitas Negeri Malang; and Mathematics Education, Universitas Papua, Indonesia.

Cholis Sa'dijah - Correspondence Author, Professor in Mathematics Education, Postgraduate School, Universitas Negeri Malang, Indonesia.

Abdur Rahman As'ari - Associate Professor in Mathematics Education, Postgraduate School, Universitas Negeri Malang, Indonesia.

I Made Sulandra - Associate Professor in Mathematics, Postgraduate School, Universitas Negeri Malang, Indonesia.

\section{REFERENCES}

Akpinar, E., Erol, D., \& Aydoğdu, B. (2009). The role of cognitive conflict in constructivist theory: An implementation aimed at science teachers. Procedia - Social and Behavioral Sciences, 1(1), 2402-2407. https://doi.org/10.1016/j.sbspro.2009.01.421

Aksoy, N. C., \& Yazlik, D. O. (2017). Student Errors in Fractions and Possible Causes of These Errors. Journal of Education and Training Studies, 5(11), 219. https://doi.org/10.11114/jets.v5i11.2679

Baser, M. (2006). Fostering Conceptual Change by Cognitive Conflict Based Instruction on Students' Understanding of Heat and Temperature Concepts. Eurasia Journal of Mathematics, Science and Technology Education, 2(2), 96-114.

Bingolbali, E., Akkoc, H., Ozmantar, F., \& Demir, S. (2011). Pre-Service and In-Service Teachers' Views of the Sources of Students' Mathematical Difficulties. International Electronic Journal of Mathematics Education, 8(1), 40-59.

Budiman, Z. B., Halim, L., Meerah, S. M., \& Osman, K. (2014). The effects of cognitive conflict management on cognitive development and science achievement. International Journal of Science and Mathematics Education, 12(August 2013), 1169-1195. https://doi.org/10.1007/s10763-013-9460-6

Djasuli, M., Sa'dijah, C., Parta, I. N., \& Daniel, T. (2017). Students' Reflective Abstraction in Solving Number Sequence Problems. International Electronic Journal of Mathematics Education, 12(6), 621-632.

Hasemann, K. (1981). Klaus hasemann on difficulties with fractions. Educational Studies in Mathematics, 12 , $71-72$.

Kang, H., Scharmann, L. C., Kang, S., \& Noh, T. (2010). Cognitive Conflict and Situational Interest as Factors Influencing Conceptual Change. International Journal of Environmental and Science Education, 5(4), 383-405. Retrieved from http://www.eric.ed.gov/ERICWebPortal/detail?accno=EJ908938\%5Cnhttp:// www.eric.ed.gov/PDFS/EJ908938.pdf

Kang, S., Scharmann, L. C., \& Noh, T. (2004). Reexamining the role of cognitive conflict in science concept learning. Research in Science Education, 34(1), 71-96. https://doi.org/10.1023/B:RISE.0000021001. 77568.b3

Kang, S., Scharmann, L. C., Noh, T., \& Koh, H. (2005). The influence of students' cognitive and motivational variables in respect of cognitive conflict and conceptual change. International Journal of Science Education, 27(9), 1037-1058. https://doi.org/10.1080/09500690500038553 
Kar, T. \& Isik, C. (2014). Analysis of Problem Posed by Pre-Service Primary Teachers About Adding Fraction in Termof Semantic Structure. Internationl Society of Educatinal Research., 2(2), 135-146.

Lee, G., \& Byun, T. (2012). An Explanation for the Difficulty of Leading Conceptual Change Using a Counterintuitive Demonstration: The Relationship Between Cognitive Conflict and Responses. Research in Science Education, 42(5), 943-965. https://doi.org/10.1007/s11165-011-9234-5

Lee, G., \& Kwon, J. (2001). What Do We Know about Students' Cognitive Conflict in Science Classroom: A Theoretical Model of Cognitive Conflict Process. Proceedings of 2001 AETS Annual Meeting, 309-325.

Lee, G., \& Yi, J. (2013). Where Cognitive Conflict Arises From?: the Structure. International Journal of Science and Mathematics Education, 11(July 2012), 601-623.

Lee, G., Kwon, J., Park, S. S., Kim, J. W., Kwon, H. G., \& Park, H. K. (2003). Development of an instrument for measuring cognitive conflict in secondary-level science classes. Journal of Research in Science Teaching, 40(6), 585-603. https://doi.org/10.1002/tea.10099

Limon, M. (2001). On the cognitive conflict as an instructional strategy for conceptual change: a critical appraisal. Learning and Instruction, 11, 357-380.

Madu, B. C., \& Orji, E. (2015). Effects of Cognitive Conflict Instructional Strategy on Students' Conceptual Change in Temperature and Heat. SAGE Open, 5(3). https://doi.org/10.1177/2158244015594662

Maharani, I. P., \& Subanji, S. (2018). Scaffolding Based on Cognitive Conflict in Correcting the Students' Algebra Errors. International Electronic Journal of Mathematics Education, 13(2), 67-74.

Ndalichako, J. L. (2013). Analysis of Pupils' Difficulties in Solving Questions Related to Fractions: The Case of Primary School Leaving Examination in Tanzania. Creative Education, 04(09), 69-73. https://doi.org/10.4236/ce.2013.49B014

Novitasari, N., Lukito, A., \& Ekawati, R. (2018). Slow Learner Errors Analysis in Solving Fractions Problems in Inclusive Junior High School Class. Journal of Physics: Conference Series, 947(1). https://doi.org/10.1088/1742-6596/947/1/012035

Oh, J. (2011). Using an enhanced conflict map in the classroom (photoelectric effect) based on lakatosian heuristic principle strategies. International Journal of Science and Mathematics Education, 9(5)(November 2009), 1135-1166.

Özmantar, M. F., \& Bingölbali, E. (2009). Sınıf Öğretmenleri ve Matematiksel Zorlukları (Primary Teachers and Their Mathematical Difficulties), 8(2), 401-427. Retrieved from http://dergipark.gov.tr/download/article-file/223550

Peled, I., \& Awawdy-Shahbari, J. (2009). Journey to the past: Verifying and modifying the conceptual sources of decimal fraction knowledge. Canadian Journal of Science, Mathematics and Technology Education, 9(2), 73-85. https://doi.org/10.1080/14926150902908776

Sela, H. (2008). Coping with Mathematical Contradictions with Peers. In Paper presented at Topic Study Group 18, ICME 11 (pp. 1-9).

Sela, H., \& Zaslavsky, O. (2007). Resolving Cognitive Conflict with Peers - Is There a Difference Between Two and Four? Proceedings of the 31 Conference of the International Group for the Psychology of Mathematics Education, 4, 169-176.

Setianingsih, R., Sa'dijah, C., As'ari, A. R., \& Muksar, M. (2017). Investigating Fifth- Grade Students' Construction of Mathematical Knowledge through Classroom Discussion. International Electronic Journal of Mathematics Education, 12(4), 383-396.

Shahbari, J. A., \& Peled, I. (2015). Resolving Cognitive Conflict in a Realistic Situation with Modeling Characteristics: Coping with a Changing Reference in Fractions. International Journal of Science and Mathematics Education, 13(4), 891-907. https://doi.org/10.1007/s10763-014-9509-1

Shein, P. P. (2012). Seeing with Two Eyes: A Teacher's Use of Gestures in Questioning and Revoicing to Engage English Language Learners in the Repair of Mathematical Errors. Journal for Research in Mathematics Education, 43(2), 182. https://doi.org/10.5951/jresematheduc.43.2.0182

Subanji. (2015). Teori Kesalahan Konstruksi Konsep dalam Pemecahan Masalah Matematika. (T. Nusantara, Ed.) (I). Indonesia: Universitas Negeri Malang.

Susilawati, W., Suryadi, D., \& Dahlan, J. A. (2017). The Improvement of Mathematical Spatial Visualization Ability of Student through Cognitive Conflict. IEJME - Mathematics Education 2017, Vol. 12, No. 2, 155-166, 12(2), 155-166. 
Toka, Y., \& Askar, P. (2002). The Effect of Cognitive Conflict and Conceptual Change Text on Students' Achievement Related to First Degree Equations with One Unknown. Hacettepe Universitesi Egitim Fakultesi Dergisi, 23, 211-217.

Wyrasti, A. F. (2016). Penelusuran Konflik Kognitif Siswa dalam Menyelesaikan Masalah Matematika. In Prosiding Seminar Nasional Pendidik dan Pengembang Pendidikan Indonesia yang Diselenggarakan oleh APPPI, Dinas Pendidikan Kota Batu, dan PGRI Kota Batu pada 21 Mei 2016 di Kota Batu, Jawa Timur (Vol. 1, pp. 73-80).

Wyrasti, A. F., Sa'dijah, C., \& Anwar, L. (2016). The Assessment of Students' Cognitive Conflict by Using Student's Cognitive Map in Solving Mathematics Problem, (2006), In Proceeding International Conference on Education.72-82. ISBN: 978-602-71836-1-2 http://pasca.um.ac.id/conferences/index.php/ ice/article/view/15

Zazkis, R., \& Chernoff, E. (2006). Cognitive Conflict and Its Resolution Via Pivotal/Bridging Example. Proceedings of the 30th Conference of the International Group for the Psychology of Mathematics Education, 5, 465-472.

Zazkis, R., \& Chernoff, E. J. (2008). What makes a counterexample exemplary? Educational Studies in Mathematics, 68(3), 195-208. https://doi.org/10.1007/s10649-007-9110-4

Zhou, G. (2010). Conceptual change in science: A process of argumentation. Eurasia Journal of Mathematics, Science \& Technology Education, 6(2), 101-110. https://doi.org/10.1007/BF00486624 